\title{
Range extenders: an innovative approach to range anxiety in electric vehicles
}

\author{
Ian Clarke* and Athena Piterou
}

University of Greenwich, Old Royal Navy College,

30 Park Row, SE10 9LS, London

Email: i.clarke@gre.ac.uk

Email: a.piterou@gre.ac.uk

*Corresponding author

\begin{abstract}
Electric vehicles have been a source of major innovation but the problem of vehicle range persists. Range extenders, auxiliary power units that can be attached to vehicles as a trailer, seek to solve the problem by providing additional range during longer journeys. This study uses patent data, social network analysis and qualitative data to examine the development of this technology. It finds that small firms have made significant progress in technological terms and have also designed credible business models. They have met resistance from larger vehicle manufacturers, however, whose preference is to wait for developments in battery density despite great uncertainty as to when these will come.
\end{abstract}

Keywords: electric vehicles; innovation; range anxiety; range extenders.

Biographical notes: Ian Clarke is a Senior Lecturer in Innovation and Enterprise at the University of Greenwich. His research interests have focused on the role of intermediary organisations in a number of different settings, including developing economy clusters. He is interested in innovation and sustainability and is researching the development and adoption of electric vehicles, particularly in relation to the problem of vehicle range. A more recent research interest has been the re-emergence of tramways and light rail in a number of different European contexts.

Athena Piterou is a Senior Lecturer in Sustainability at the University of Greenwich. Her past research projects include a study of the emergence of electronic books as a prospective transition pathway in the print-on-paper regime and an examination of community renewable energy in London. She has worked on INTERREG funded projects regarding small business innovation and the promotion of renewable energy in the UK and France. Her current research includes the examination of cluster formation in the creative industries. 


\section{Introduction}

An enduring problem faced by electric vehicles (EVs) is concern amongst potential customers about the range of the vehicle and, despite significant investment by automobile manufacturers, progress in increasing battery capacity has been slow (Dijk, 2016). For this reason a number of alternative possible solutions to the range problem have been tried and this paper will examine the development of the one of these, auxiliary range extenders.

Auxiliary range extenders are external power units that can be attached to EVs to provide power during longer journeys and their developers have sought to learn from the problems of battery swapping, an earlier attempt to solve the EV range issue which has now largely been abandoned. Their attraction lies in the recognition that, for most EV users, range is not a problem for day-to-day use when journeys completed are predictable and relatively short (Pearre et al., 2011). For this reason the power that a large, expensive, battery could provide is not needed and the approach is instead to provide this as an add-on on days when longer journeys are to be made.

This paper uses both quantitative analysis based on patent data and qualitative analysis (interviews and site visits) to examine the development of auxiliary range extenders. The paper examines the technological challenges faced by range extenders, considering how they aim to provide a 'modular' approach to the range problem. It also considers the problems in developing a workable business model for this technology. Particularly relevant in this case is that range extender innovation has come from small firms, but they are dependent on cooperation and partnership with large firms to make the approach a success. Interviews were conducted with small firms in order to identify their technological progress and proposed business model. Patents relating to the technology also indicate to what degree firms engage in collaborative research and development (R\&D).

Large automobile manufacturers are currently reluctant to pursue this option; instead investing heavily in improving EV battery technology with the hope that results from this will come quickly. Moreover, manufacturers have an underlying desire for future automobility to develop as closely as possible to for internal combustion engine (ICE) cars and for this reason auxiliary range extenders are questioned. The paper will examine, therefore, how the firms that have developed range extenders are attempting to interact with car manufacturers, looking at some of the problems faced and the strategies designed in response to these.

The paper will proceed as follows. Section 2 will review the literature on range anxiety and assess its relevance to the future development of EVs while Section 3 will introduce the auxiliary range extender concept, outlining some of the technological and business model challenges they face. Section 4 will outline the methodology to be followed in the study, consisting of a combination of patent and network analysis and qualitative research. Section 5 will present the results from the research and interpret the main successes and challenges experienced by range extenders while Section 6 will conclude by analysing this evidence in the context of the wider development of EVs. 


\section{Range anxiety: needs and preferences}

As EVs began to re-emerge in the 1990s 'range anxiety' as a distinctive problem began to be recognised (Nilsson, 2011), vehicle range being identified as a problem for the first time since the development of a petrol station infra-structure in the early 1900s. Range anxiety refers to concerns customers have about being stranded when using their EV, being in a situation where they have run out of charge and do not have access to charging facilities. Its complexity lies in the fact that it is affected by both the personal traits of EV drivers but also by conditions both inside and outside the EV.

Technologically the range problem originates in the limitations of the EVs batteries. The fact that the energy density of EV batteries is significantly lower than that of carbon fuels affects not only range but also the size and weight of the battery a vehicle needs to carry. Range anxiety is also related, however, to how a motorist is planning to use their vehicle. For many drivers this will be for a short journey to work, school or leisure pursuits, but range anxiety increases when more lengthy journeys are taken (Frank et al., 2012).

For potential EV users range is a difficult problem to understand as there are a huge number of hybrids (including plug-in hybrids) and EVs (including those with the option of internal range extenders) on the market, each with different ranges, charging times and pricing structures. Tesla's proprietary technology complicates the situation further in that their high media exposure shapes public knowledge of EVs, even if their products are out of the price range of many consumers. Range is also complex because it is constantly changing and subject to promises - sometimes realistic, sometimes exaggerated - from vehicle manufacturers. Central to this complexity is the varying relationship that exists between range and price.

Frank et al. (2012) argue that range anxiety is mainly a psychological barrier and introduce the concept of comfortable range, which can be defined as the preferred range safety buffer of a user. Comfortable range varies from one individual to another and is comprised of both physical and subjective factors. The physical situation consists of both the range of the car and the charging options available to the user, being the home, work or public amenity-based. The subjective position is more complex, referring to how range is both interpreted and managed by the user. Different individuals have differing attitudes to risk, and differing propensities to deal with stress, thus affecting their comfortable range (ibid.). In a six-month field trial of 40 early adopter EV customers, for example, it was found that users were comfortable with utilising approximately $75-80 \%$ of their available range resources (Franke and Krems, 2013b).

Range anxiety can also vary according to level of experience an EV driver has (Rauh et al., 2015). Field studies found that range preferences decrease over the first three months of EV use and higher range preferences were also found to be related to the range of the driver's familiar ICE vehicle and higher than average range needs (Franke and Krems, 2013a). Only customers with EV experience, however, seemed to be able to rely on accurate estimates of their range needs when constructing their range preferences (ibid.). A study of mainstream consumers regarding their attitudes to the adoption of battery EVs or plug-in hybrid vehicles suggested that these vehicles were still seen as works in progress with consumers believing that the contemporary generation of models would soon become superseded (Graham-Rowe et al., 2012). Besides concerns on range anxiety which affected the consumer's confidence in the vehicle, the need to adapt daily 
routines and driving habits because of the long charging time was also observed (ibid.). Although attitudes towards EVs change with experience, negative evaluation of range does not (Rezvani et al., 2015).

Understanding the disjunct between drivers actual range needs, calculated on their usage through several studies of detailed driving behaviour, and their expressed range preferences is important. Pearre et al. (2011), for example, considered whether battery range limitations are compatible with gasoline enabled driving habits, collecting data on daily driving patterns from close to 500 ICE vehicles in the USA. They found that $9 \%$ of the vehicles never exceeded 100 miles $(=160 \mathrm{~km})$ in one day and $21 \%$ of the vehicles never exceeded 150 miles $(=240 \mathrm{~km})$ in one day. These drivers could substitute a current $\mathrm{EV}$, with its limited range, without any adaptation to their driving habits.

A further group of drivers was analysed in terms of adaptations they could make, examples of which included stopping to re-charge during a journey, borrowing an ICE vehicle or combining certain tasks in a single journey. For these drivers a current EV would meet the needs of $21 \%$ of drivers if they are willing to make two adaptations during a year and $32 \%$ of drivers if they are willing to make six adaptations during a year (ibid.).

Needell et al. (2016) combining travel surveys with GPS data, also studied the US driving behaviour.

They investigated the energy requirements of personal vehicle trips across the US and found that those for $87 \%$ of vehicle days could be met by existing and affordable EVs. In addition, this figure was similar across diverse cities even when total usage of the vehicle is very different. Evidence from Europe also produces similar results, with Bunzeck et al. (2011) finding that $61 \%$ of European participants drive less than $100 \mathrm{~km}$ per day and $24 \%$ less than $20 \mathrm{~km}$. Only $15 \%$ of drivers in this study drove more than $150 \mathrm{~km}$ per day.

Overall, therefore, a variety of studies from different parts of the world show that the currently common 100 mile $(=160 \mathrm{~km})$ range of EVs is sufficient for a sizeable share of the car driving population (Franke and Krems, 2013a). In addition, attitudes to range anxiety differ depending on the vehicle category: although the micro/city cars category is less affected by range, this category is also more prices sensitive (Lieven et al., 2011). On the other hand there is good potential for EVs as commercial cars (e.g., taxi fleets); in this context, business models can be more adaptable (ibid.). For those who require higher range, however, a series of adaptations can be made, one approach to this being the development of range extenders.

\section{Range extenders as range adaption}

While EVs are able to deal with the majority of drivers' needs a small number of high-energy days still remain (Needell et al., 2016) and, for this reason, either organisational or technology adaptations remain relevant as a way to deal with these days. This problem is most easily solved for households that own more than one vehicle (Pearre et al., 2011). For a multi-vehicle owning household, for example, Kurani et al. (1996) found that a driving range limit on one household vehicle will not be an important barrier to purchase of an EV, assuming a vehicle can be recharged each day with a full charge. For such households the ability to manage their demand through adequate charging facilities, and plan needs carefully, is more important than absolute range. 
Another route to deal with the problem is through vehicle hire. While this has become increasingly flexible for short-term car hire, hiring a car for a longer journey remains both expensive and inconvenient. It invariably involves a journey to pick up and return the car, for example, and in addition often a car hire period will include periods when the car is not being used which have significant cost implications.

A solution to overcome these difficulties and provide more flexibility to EV users is the advent of range extenders. A distinction needs to be drawn between two different uses of the term 'range extenders' in the automotive industry. This paper is concerned with auxiliary range extenders. Auxiliary range extenders are external trailers which are attached to EVs solely for the time when their use is needed. Both firms that are considered in this article, therefore, are producers of auxiliary range extenders.

As mentioned, however, the term 'range extender' is also used within the automobile industry to refer to a particular type of hybrid car where the power unit (the range extender) is located inside the vehicle. This range extender is a permanent feature of the vehicle but, unlike in other hybrid vehicles, it does not directly power the wheels. Harrop (2018) identifies three generations of these type of range extenders: the first generation of 'off the shelf'. ICEs are being replaced by second generation piston engines which are designed to fit into a series hybrid, while more radical options such as micro turbines and fuel cell engines are used in third generation range extenders.

Returning to auxiliary range extenders, these have developed in the context of EVs as an emerging technology which requires complementary products and services in order to function efficiently. There is no clear consensus on what constitutes an emerging technology but they are characterised by radical novelty, quick growth, coherence, strong impact, uncertainty and ambiguity (Rotolo et al., 2015). The phenomenon of 'range anxiety' suggests that the development of a complementary charging infrastructure is required for EVs to achieve a greater level of consumer acceptance. Like many products EVs are characterised by network effects as increasing number of users would enable the creation of the charging infrastructure (Stringham et al., 2015).

$\mathrm{EVs}$, therefore, form a complex product ecosystem where the core product is supported by additional products and services that are occasionally subsidised (ibid.). Range extenders can be considered analogous to portable chargers for mobile phones as they are a complementary product that addresses the issue of range anxiety. There is only limited research regarding auxiliary power units (APUs) for EVs although hydrogen fuel cell APUs as a supplementary unit in ICE cars have been considered (Agnolucci and McDowall, 2007).

The paper examines two current attempts to develop auxiliary range extenders, EP Tender from France and BVB Innovate from Germany. Both firms have learnt from the failure of battery swapping, which involved exchanging a discharged battery for a fully charged one at a specially designed swapping station. This has been attempted by the firm Better Place, in Denmark and Israel, and also was experimented with, but not pursued, by Tesla. Problems with the approach are the high costs of swapping stations and limited choice available to drivers.

EP Tender and BVB Innovate have developed different designs for their range extenders and both firms seek cooperation and partnership from larger manufacturing firms. While such partnership will require an innovative business model, this is problematic as a theme in the business model literature, particular for large firms, is clear bias towards the status quo. This is described by Chesbrough (2007) as the 'business 
model innovation leadership gap', referring to how in most firms only a limited number of people have the authority to instigate organisational innovations and there is a fear of the time-frame, risks and sharp learning curves involved.

Potential conflict with the existing business model also inhibits change, as a new business model needs to achieve 'buy-in' from important constituencies inside the firm, and also sometimes outside, before it can be successfully implemented. In the range extenders case such outside constituencies could include customers, storage sites and repair organisations.

Despite this, however, there are occasions when business model choice has operated as a moderating influence between technological development and performance outcomes for a firm and sometimes both technological and business model innovation combine (Baden-Fuller and Haefliger, 2013). A less static, more transformational, perspective on change is also provided by Demil and Lecocq (2010) who argue that in certain circumstances business models can be dynamic and emergent, different components of the model interacting and evolving in response to both internal and external processes. Two stimuli to such change, both of relevance to range extenders, are new technology and sustainability initiatives.

Several examples exist of how sustainability goals can stimulate business model change (Boons and Lüdeke-Freund, 2013). For example, in the automobile industry the dominant business model emerged in the 1920s (Wells and Nieuwenhuis, 2012) and the industry has traditionally been conservative in its approach to business model change (ibid.; Kley et al., 2011). Sustainability challenges have, however, challenged this conservativeness (Orsato and Wells, 2007; Wells, 2010) and the advent of EVs has lead to a period of business model innovation (Weiller et al., 2015; Proff and Fojcik, 2015; Kley et al., 2011). This has included willingness on the part of automotive firms to diversify into providing complementary products (Krommes and Schmidt, 2017) and into service provision (Kessler and Stephan, 2013).

\section{Methodology}

This section will explain how both quantitative and qualitative methods will be used to examine the development of range extender technology and associated business models. The following research questions will be addressed:

- Which firms have developed range extenders and what challenges do they face?

- What does patent data reveal about firm activity in the range extender field?

The first research question will be answered primarily through the use of qualitative data collected from the French firm EP Tender and from the German firm BVB Innovate. A visit was made in June 2016 to the EP Tender headquarters and workshop in Poissy on the outskirts of Paris. As a part of the visit an interview was conducted with the founder of the firm and, in addition, a demonstration test run was undertaken so that the operation of the tender could be observed.

A visit was also made to the headquarters of BVB Innovate in Stuttgart in October 2016. As a part of the visit an interview was conducted with a representative of the firm and the visit also provided an opportunity to learn more about the automobility culture in Stuttgart, and wider Germany, into which it is hoped to launch the Mobat. In addition to 
these visits evidence from firm reports and websites, motor industry and mainstream websites and publications, industry reports and academic papers has been gathered to provide a background context to the development of the technology and the stages in the two firms' development.

The interviews conducted with both firms were semi-structured. Three primary areas for questioning were identified prior to the interviews:

- Technological developments - this provided the opportunity to question each firm on the origins of their range extender and the major technological milestones in its development.

- Business model development - this provided an opportunity to learn about the proposed way in which both firms plan to commercialise their product. As BVB Innovate has a longer history there has been considerable evolution and adaptation in their case which the interviews will explore.

- Partnerships - this included partnerships which the firm has either already entered into or are attempting to establish. This is a crucial area because both firms need to work with car manufacturers to gain wider acceptance of the range extender idea.

The semi-structured interview design provided flexibility, particularly in the case of EP Tender where the opportunity to take part in a demonstration run meant that the visit was longer than that made to BVB Innovate. In addition, not all of the discussion with the representative from EP Tender was transcribed, instead a concentration being made on the three areas outlined. The presentation of results will be organised according to the three main areas of investigation that have been identified and the opportunity will be taken to make comparisons between the two firms. In addition, in the discussion and conclusion section, some analysis will be done of the prospects for range extenders as a whole.

The second research question will be answered by using patent mapping and social network analysis methods to identify technological developments and collaborative R\&D activity regarding range extenders. Besides being publicly available patents have a number of advantages as a source of innovation data: they cover the whole population of innovating firms, they are maintained and update over time and they are standardised in structured formats (Lo Storto, 2006; Griliches, 1990) Patent documents and the related bibliographic data are used to map the linkages between innovators and to measure to what extent innovation activity in a particular field is collaborative (Beaudry and Schiffauerova, 2011). Social Network Analysis is used to visualise and analyse the collaboration networks among organisations active in the research field. In addition, thematic analysis is used to identify the themes and sub-themes of technological areas that are represented in the data.

Patent mapping is a quantitative methodology that can lead to the identification of technological trajectories (Verspagen, 2007). The joint analysis of scientific publications, research grants and patents allows for the representation of the 'triple-helix interfaces'; between academia, government and industry (Mogoutov et al., 2008). Structured patent data available from databases such as the US Patent Office and World Intellectual Property Organisation (WIPO) can indicate the science base of technology fields (Leydesdorff, 2004). Bibliometric proposals and publications are useful indicators of emerging technologies at the early stages of technology development while patents 
capture knowledge evolution later in the technology cycle, closer to the commercialisation stage (Cozzens et al., 2010). R\&D funding statistics are an additional source of data that can aid policy development and strategic decision making regarding the evaluation of competing technologies but there are concerns regarding their quality and availability (Hopkins and Siepel, 2013). Hence, scientific publications and patents can complement financial data when studying technological emergence (ibid.).

EVs are considered a climate change mitigating technology. In recent years there has been increasing interest in the role of patents and climate change mitigation technologies as the United Nations Framework Convention on Climate Change has recognised the role of intellectual property rights in addressing these challenges (Veefkind et al., 2012). In addition, the WIPO has developed a Green Inventory of Environmentally Sound Technologies that lists the relevant IPC classes (IPC Green Inventory, n.d.). A number of patent studies have been conducted in the area of EVs addressing issues of business strategy and public policy. Considering EVs as a complex product system, Pilkington and Dyerson (2006) have examined the technological capabilities of incumbent and new entrant actors in relation to the US regulatory policy. Earlier work by Pilkington et al. (2002) addressed how firms develop links with competitors in order to develop the technology. Wesseling et al. (2014) have analysed the data longitudinally since the 1990s comparing the different patterns of growth for patents involving battery EVs, hybrid EVs and hydrogen fuel cell vehicles. Ranaei et al. (2016) conducted an analysis using patent data on electric and fuel cell vehicles between 1990 and 2010 and they predicted that EVs will achieve a higher R\&D share and faster growth rates.

The formation of the search query regarding range extenders is explained in the Appendix. The structure of the search query should delineate the boundaries of the technologies under study by identifying a wide range of relevant patents and patent applications while avoiding the inclusion of records that are not directly related to the range extender concept as defined for this paper.

\section{Results}

\subsection{Data analysis of the patent dataset}

Among the 618 records in the dataset there were 384 patent applications, three utility model ('petty patents') applications, 127 granted utility models and 104 granted patents. These intellectual property records are structured into fields including application and publication numbers and dates, countries or jurisdictions where protection is sought, information regarding the inventors, applicants and assignees (owners) of the invention, and information on the record's classification according to different classification schemes. Furthermore, the dataset includes information regarding the content of the patent such as the number of claims made, the title, abstract, link to the full-text and citation counts. Information on patent families is also provided. Applicants often apply to patent the same invention in more than one jurisdiction. Hence, patent families refer to patent applications that cover the same or similar technical content (simple and extended patent families) (EPO, n.d.).

There is usually a 12 to 18 months lag between the application and the granting of the patent (WIPO, http://www.wipo.int/sme/en/faq/patent_faqs.html) which would suggest a recent surge in application activity and relatively large proportion of applications still 
being processed. Table 1 indicates the current legal status of the records. The majority of the records are still active (granted or under processing).

Table 1 Legal status of the records

\begin{tabular}{lccccc}
\hline & Application & $\begin{array}{c}\text { Granted } \\
\text { utility model }\end{array}$ & Patent & $\begin{array}{c}\text { Utility model } \\
\text { application }\end{array}$ & $\begin{array}{c}\text { Grand } \\
\text { total }\end{array}$ \\
\hline Active - granted/applied & 285 & 103 & 76 & & 464 \\
Inactive - ceased/lapsed/expired & 2 & 1 & 11 & & 14 \\
Inactive - expired & 12 & 15 & 7 & & 34 \\
Inactive - non-payment & 14 & 5 & 17 & 1 & 37 \\
Inactive - & 11 & & 2 & & 13 \\
rejected/refused/suspended & 51 & 3 & & 2 & 56 \\
Inactive - withdrawn/surrendered & 375 & 127 & 113 & 3 & 618 \\
Grand total & & & & &
\end{tabular}

Data regarding publication and priority country act as a proxy to identify where R\&D activity takes place. Patents submitted through the European route or under the international Patent Cooperation Treaty mention a number of designated countries where protection is sought. The priority country is the country where the patent is first filed before being extended to other countries (OECD, n.d.). It may coincide with the applicant's country of origins and it indicates that the particular market is considered significant. Figure 1 indicates the top ten priority countries in the dataset.

Figure 1 Top 10 priority countries (see online version for colours)

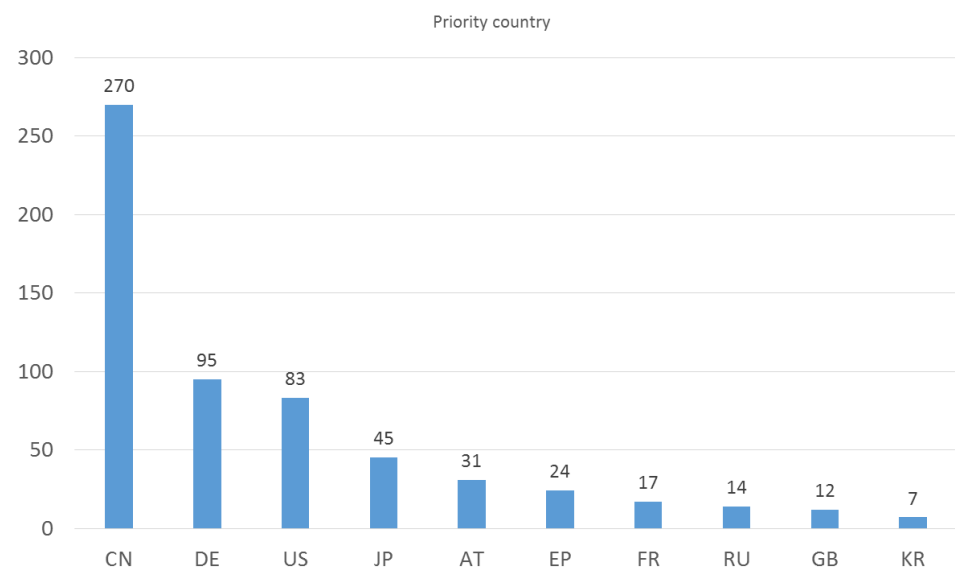

China is more frequently listed as a priority country. However, patents filed in China are not likely to be highly cited. Figure 2 indicates the average forward citation counts (for the patent and the members of its simple family) per priority country. For instance, this variable for China shows how many patents on average have cited a patent/patent application submitted with China as a priority country and its simple family members. We have included the citations for simple family members as these cover the same technical content. Forward citations act as a proxy measure for the importance of a 
patent. Patents submitted through the European Patent Convention route (EP) are more likely to be highly cited.

Figure 2 Forward citation counts by priority country (see online version for colours)

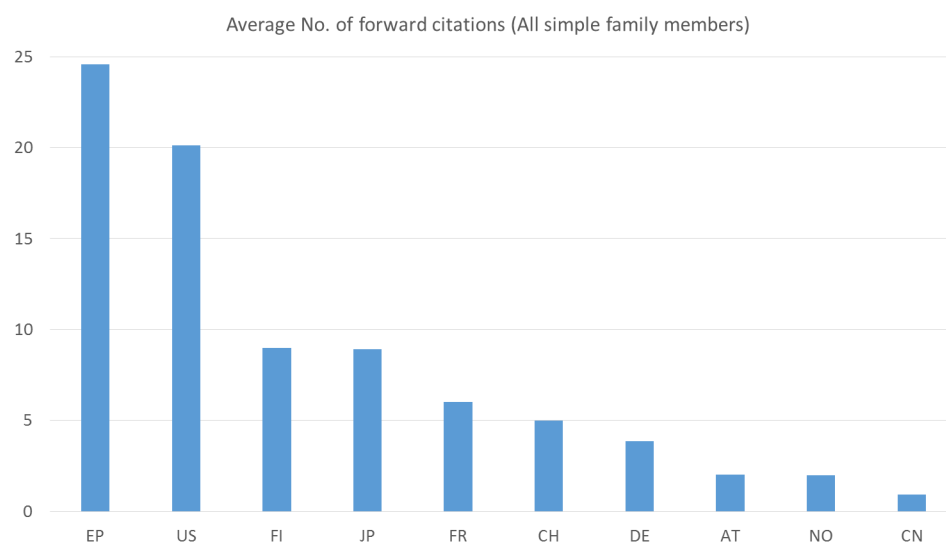

Austrian firm AVL List Gbmh holds most records (33) in the dataset. They are the largest independent company focused on the development of powertrain systems. Robert Bosch Gbmh follows with 14 records. Both companies act as suppliers and consultants to automotive manufacturers. Among car manufacturers BMW, Audi and Renault are represented among the top ten assignees. A number of companies develop range extenders or trailers for specialist vehicles such as sports vehicles and snowmobiles (Swiss Auto Power Sport LLC, Polaris).

Figure 3 The co-invention network of the top 10 assignees (see online version for colours)

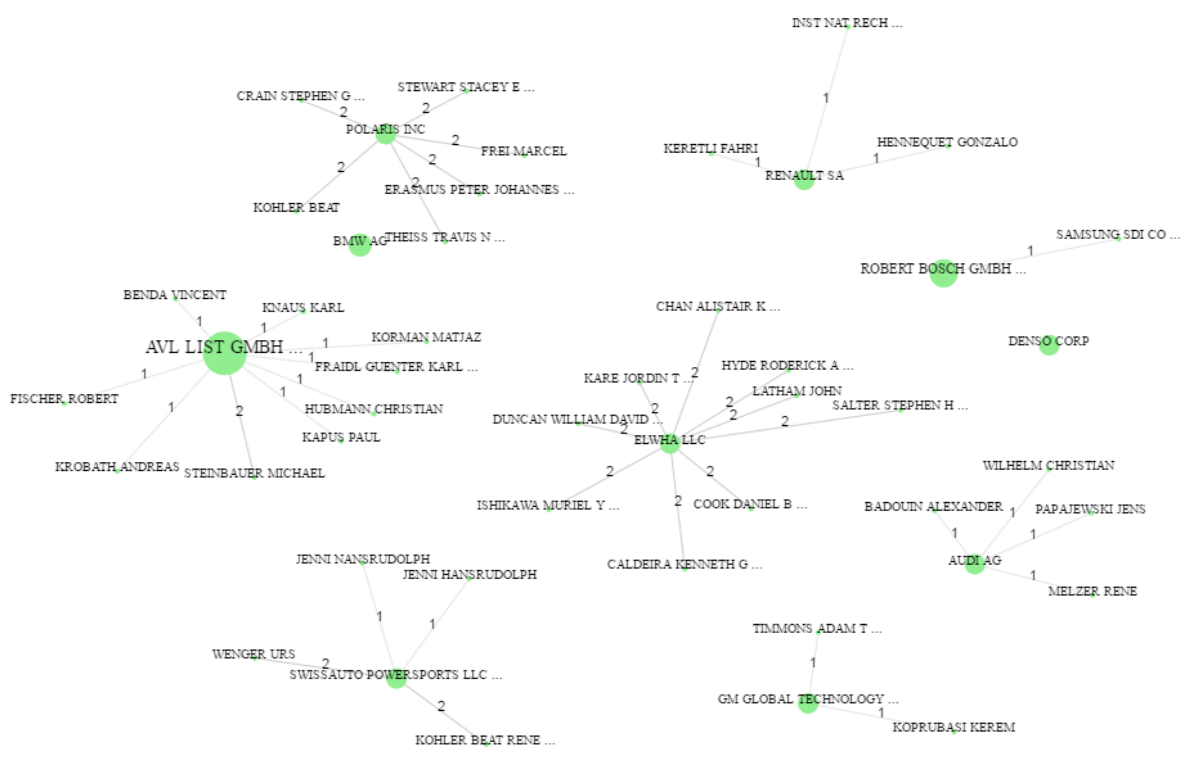


Figure 3 shows the links between the top ten patent assignees (owners of the intellectual property) and their co-assignees. The resulting network shows limited evidence of collaboration between companies although some of the companies are co-assignees with their employees in some patents. However, there is collaboration between Renault and Samsung on a range extender for EVs in one patent which belongs to a family with five patents. Otherwise, there is hardly any evidence of collaboration among car manufacturers and other companies.

Patent classification and thematic analysis are used to identify what technological area the R\&D activity covers. Using the cooperative patent classification (CPC) scheme the top ten patent classes are shown in Table 2.

Table 2 Top 10 patent classes

Y02T10: climate change mitigation technologies relating to transportation/road

B60L11: electric equipment or propulsion of electrically-propelled vehicles; magnetic suspension or levitation for vehicles; electrodynamic brake systems for vehicles, in general/electric propulsion with power supplied within the vehicle.

B60K6: arrangement or mounting of propulsion units in vehicles/arrangement or mounting of plural diverse prime-movers for mutual or common propulsion, e.g., hybrid propulsion systems comprising electric motors and internal combustion engines.

B60L2240:electric equipment or propulsion of electrically-propelled vehicles; magnetic suspension or levitation for vehicles; electrodynamic brake systems for vehicles, in general/control parameters of input or output; target parameters.

Y02T90: climate change mitigation technologies relating to transportation/enabling technologies or technologies with a potential or indirect contribution to GHG emissions mitigation.

B60L2200: electric equipment or propulsion of electrically-propelled vehicles; magnetic suspension or levitation for vehicles; electrodynamic brake systems for vehicles, in general/types of vehicle.

B60W10:conjoint control of vehicle sub-units of different type or different function; control systems specially adapted for hybrid vehicles; road vehicle drive control systems for purposes not related to the control of a particular sub-unit/conjoint control of vehicle sub-units of different type or different function (for propulsion of purely electrically-propelled vehicles with power supplied within the vehicle B60L 11/00).

B60W20: conjoint control of vehicle sub-units of different type or different function; control systems specially adapted for hybrid vehicles; road vehicle drive control systems for purposes not related to the control of a particular sub-unit/control systems specially adapted for hybrid vehicles.

B60L15: electric equipment or propulsion of electrically-propelled vehicles; magnetic suspension or levitation for vehicles; electrodynamic brake systems for vehicles, in general/methods, circuits, or devices for controlling the traction-motor speed of electrically-propelled vehicles.

B60W2510: conjoint control of vehicle sub-units of different type or different function; control systems specially adapted for hybrid vehicles; road vehicle drive control systems for purposes not related to the control of a particular sub-unitInput parameters relating to a particular sub-unit.

The links between the patent classes are shown in Figure 3. The strength of the link between two classes indicates the number of records where both classes were listed. 
Figure 4 Links between patent classes (see online version

for colours)

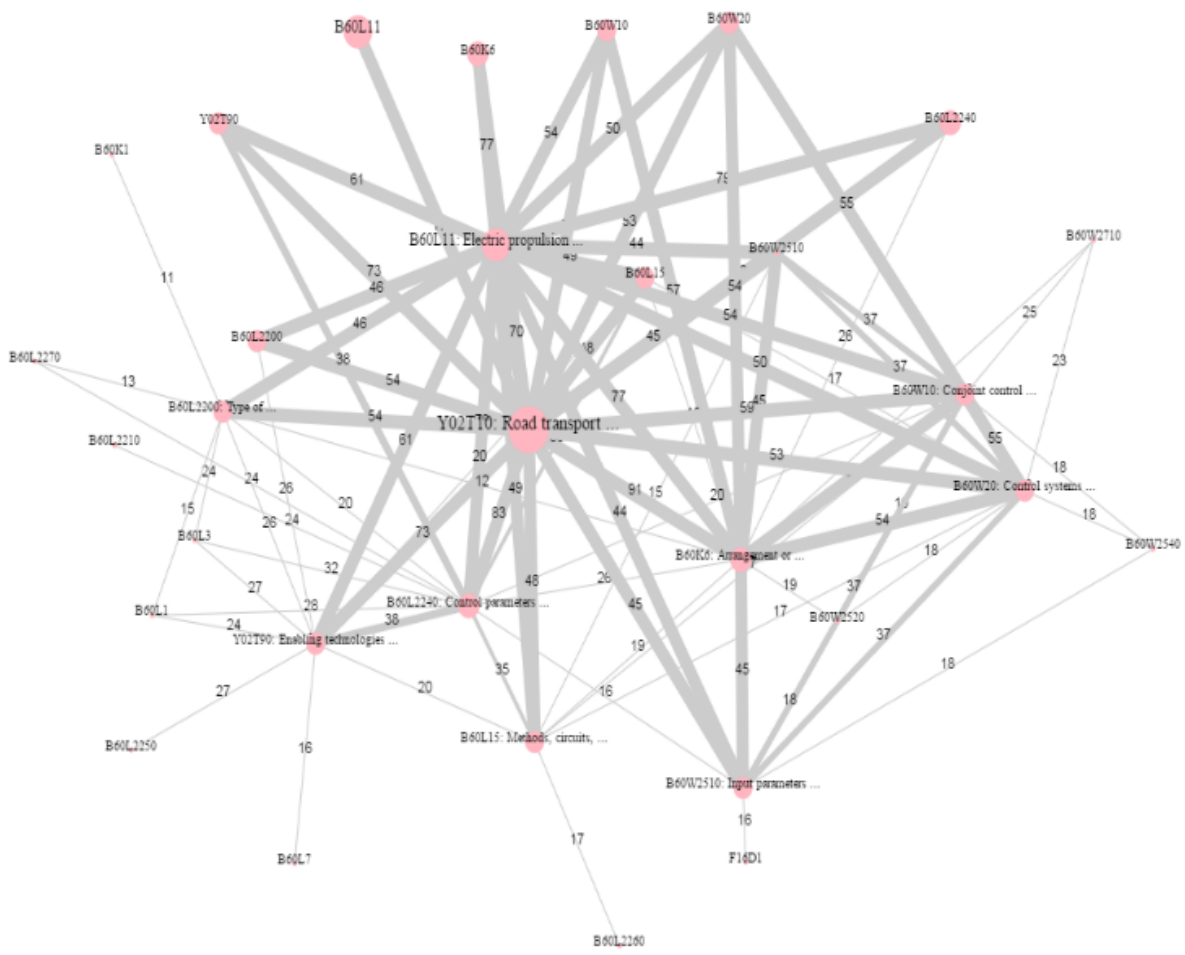

Thematic analysis was undertaken to identify the technological themes covered in the patent records.

\subsection{Case studies: EP tender and BVB innovate}

EP Tender is a French firm based in Poissy, in the western suburbs of Paris. The firm was a setup by a French entrepreneur who, having observed the problems that battery swapping firm Better Place had experienced, sought to develop range extenders as a more flexible approach to sustainable automobility. BVB Innovate is a German technology and engineering firm, based in Stuttgart, with research, development and consultancy experience in the fields of energy and e-mobility. It has a longer history than EP Tender and has persisted with the range extender concept through a number of different incarnations. The following will compare and contrast both firms' activities in the areas of technological developments, business models and partnerships. It will seek to identify the challenges each firm has faced and how they have responded to the external environment.

\subsubsection{Technological developments}

The range extender developed by EP Tender uses a standard combustion engine and a fuel tank to provide energy while driving, connecting to the vehicle through the mounting 
of a tow bar. The unit is connected in parallel to the EV's battery by inserting a junction box capable of managing vehicle diversity and ensuring no modifications are needed to a standard EV. Backing of the car is achieved through a self-steering feature using standard fixed wheels when going forward but smaller steering wheels when going backwards. This, in combination with a backing radar system, ensures manoeuvrability despite an extra 1.3 metre of length. The unit is designed to be compact and relatively light and, in addition, incorporates luggage storage space.

BVB Innovate first developed a range extender, called the E Buggy, in the late 1990s which was designed to be used with the Renault Zoe. BVB Innovate worked with partners on the technological challenges in manufacturing the unit but, for a number of reasons, found that "the timing was difficult for acceptance" (Firm interview 2, 2016). The range extenders developed by the firm use zero-emission lithium-ion batteries, in contrast to the ICE used by EP Tender. As it has developed its units since that time it has been able to increase the power-density of the batteries used.

In 2015 BVB Innovate, together with spin-off company Nomadic Power who took over responsibility for marketing, received $€ 2$ million in funding from the European Commission (Horizon 2020 framework). This funding allowed the building of six units, which were now known as Nomads, for testing purposes. An important development was that these units were now seen as multi-functional devices which, as well as acting as an external range extender, were also suitable for use as mobile charging units (see the business model section below for a full explanation of this). Since that time the unit has been renamed again as the Mobat and in this stage of development the multi-functional design of the Mobat has been enhanced through the development of different types of Mobats. A new version, which could be described as a bigger brother of the Mobat, is more powerful and has the capacity to charge four vehicles simultaneously.

\subsubsection{Business model development}

The business model proposed by EP Tender plans that customers would pick up a unit from designated rental points located approximately $50 \mathrm{~km}$ apart. In large cities these will be located at ring road crossings, for example the M25 in London providing easy motorway access, while smaller cities will have rental points at commercial centres on the cities periphery. Users will be able to book the unit via a smartphone app in advance of their trip. A pay per use model is planned - for example a customer going from London to Scotland, for a two week holiday, would only pay rental for the days of the journey each way.

Rental points can also be flexible, setup within 24 hours in relatively cheap places to rent, possibly in existing garages. They can also respond to seasonal changes, the summer holiday period for example, and to special events like music festivals (Firm Interview 1, 2016). The advantage of the unit for customers is that they can continue to use their own car, convenient if packing for a holiday for example. It can also be combined with using other charging facilities available at a destination. The aim, therefore, is for cost to be competitive against hiring an ICE for the trip or, indeed, against ownership of a second car. Pricing models are also planned to reflect peak periods and early booking.

The business model proposed by BVB Innovate, while initially similar to EP Tender, has evolved as the firm has monitored and assessed market reactions to their products. In particular a change came from 2015 onwards when the focus of the firm evolved to promoting their units as "a 'charge-anywhere' service for EVs" (Firm interview 2, 2016). 
This was envisaged as operating in a number of contexts, the firm's services being useful for short-term hire firms of EVs who could renew the availability of their vehicles without needing to take them physically to a charging station. Valet recharging was aimed at firms planning to run an e-vehicle fleet and aims to offer a re-charging service in the firm's car-park, recharging up to four vehicles at a time. In addition, the firm planned a breakdown service which gives an EV which has been stranded the option to be recharged in situ without being towed to the nearest charging point.

\subsubsection{Partnerships}

Both firms interviewed identified building partnerships with large vehicle manufacturers as the most significant challenge they have faced. EP Tender has discussed with a number of firms their unit's functionality via the junction box and continues to actively pursue partnerships. It seeks to raise the profile of the unit through demonstration projects, attendance at a variety of industry events and direct contact with car manufacturers (Firm Interview 1, 2016).

In its early days BVB Innovate partnered with Renault in working on the development of the E-Buggy. As their work has developed, however, the firm has identified intrusion into car systems as a big barrier. The experience of the firm is that for car manufacturers, concerned about regulations and security, "even opening the engine bonnet is a big challenge" (Firm interview 2, 2016). For BVB Innovate, therefore, the service model has the potential to be much less problematic and accepted by large firms, overcoming regulation, insurance and safety problems.

BVB Innovate is involved in testing the service project in its home city of Stuttgart, where there is local government sympathetic to sustainability issues and targets on air pollution (Firm interview 2, 2016). This provides an opportunity for the firm to potentially work with parking lots and, for example, supermarket chains. To compare both firms, therefore, they can be characterised as being in a research and consultation stage and immediate mass production of their units is not yet feasible for either firm.

\section{Discussion and conclusions}

The data that has been presented will now be interpreted and some general conclusions reached on the development and prospects for auxiliary range extenders. The analysis of the patent data reveals that there is only limited engagement by the major vehicle manufacturers suggesting that this is not a priority field of investment. Instead, many patents in the field apply to niche vehicle markets such as snowmobiles or sports vehicles. The network data regarding patent assignees also indicates only a limited degree of collaboration. However, additional data such as information on financial and licensing agreements could supplement the patent data to provide a more complete account of collaborative activity.

The analysis also reveals that a substantial proportion of innovative activity relating to range extenders is of an incremental nature as there are a relatively large proportion of granted utility models in the dataset. Utility models or 'petty patents' is a form of intellectual property protection available only in some countries and they are easier to obtain than a patent: demonstration of novelty is still required but the need to demonstrate the non-obviousness of the invention and the specific 'inventive step' is less pronounced 
or even lacking altogether (WIPO, http://www.wipo.int/sme/en/ip_business/utility_ models/utility_models.htm). Furthermore, utility model applications are quicker and cheaper to process (ibid.). Hence, they are more likely to refer to incremental innovation, in the form of an improvement or adaptation to already existing product; finally, they mostly relate to mechanical invention (ibid.).

The data from the patent classifications, and the thematic analysis, also indicates that range extenders are a related technology to the development of hybrid power trains. Although the focus of this paper has mainly been on auxiliary range extenders the analysis has revealed that some of the highly represented patent classes refer to hybrid propulsion systems and to hybrid systems for EVs.

Considering geographical distribution China is ranked first as a priority country, yet Chinese records receive fewer citations. This may suggest they are relatively less important. Wang and Kimble (2011) question whether China could leapfrog to EVs and the top ten Chinese automobile groups have engaged in EV projects. The investment in range extenders thus fits with the policy to increase the proportion of low energy vehicles in the country. Generally, applicants tend to file for protection first in their country of origin although patents submitted through the European route are popular.

Concerning the BVB Innovate case study it has engaged in patenting activity holding one German patent regarding the use of range extenders in EV. It has also filed a patent application under the Patent Cooperation Treaty to extend this patent to a number of countries. Also, it has filed a patent application for a Relay station for docking, interchanging and restoring trailer-based range-extenders. The manager of EP Tender has also been granted patents regarding the connection of the road trailers to the car and the patent has been submitted through the international route, with France as a priority country. An additional patent submitted through the European route focuses on safety issues.

Considering now the qualitative analysis both EP Tender and BVB Innovate have learnt from the failure of Better Place and battery swapping, in particular seeking to avoid the need for an expensive infra-structure. Both firms self-identify as developing a disruptive innovation (Segard and Baumgärtner, 2015) and in this sense have been negatively affected by Better Place's decline as there is now more cautiousness towards new technology and innovative business models addressing the range problem.

Taking into account the innovative nature of their product both firms face common challenges in achieving consumer acceptance. For some consumers there exists a fear of attaching a large trailer on to the back of the vehicle and the associated difficulties in manoeuvring. Another more psychological barrier, especially for the tech-enthusiast EV user, could be that part of the attraction is that their car is a cutting edge, fashionable product so the attachment of a trailer might challenge that image. This is particularly relevant in the case of EP Tender since their range extender uses an ICE.

Of relevance is how the two firms have arisen in the different institutional contexts of Germany and France with different expectations, and levels of support, for sustainable entrepreneurship. The Mobat has also been developed in the context of a larger firm, which is involved in other energy projects, while EP Tender is a firm solely devoted to this enterprise. It is significant that both views each other as allies in promoting the merits of range extenders on a precompetitive basis but recognise that moving forward they are competitors. The major problem faced by both firms is building partnerships with large 
car manufacturers. In response to this challenge the focus of each firm has evolved in different directions.

In the EP Tender business model the units will be available for 'on-demand' rental, to be collected by customers en route to their destination. The model has the potential for a low cost to customers but this depends on achieving a critical mass of customers which would allow the maintenance of a sufficient number of rental points. Customer concerns include fears over the process of attaching the trailer and fears over the possibilities of rear-end collisions while driving. The unit's providers also have to consider the road regulations on trailers in the different countries in which they plan to operate. In addition to overcoming these concerns a major challenge for EP Tender is the need for manufacturers to allow the junction box inside their cars and persuading them to do this is a complex task (Firm Interview 1, 2016).

BVB Innovate, having experienced similar problems in persuading car manufacturers to accept an attachable trailer, has adapted their business model to an offer of mobility as a service. Their aim is to introduce a mobile 'charge-anywhere' service, incorporating options of breakdown, valet and fleet charging and also making use of their units as energy sources for festivals and other live events. The challenge for this firm is assessing the potential level of demand for such a service and this is something which is currently being researched (Firm Interview 2, 2016).

Considering these two different focus's, their prospects for success can be assessed on their relative attributes and weaknesses compared to other possible solutions to the range problem in EVs. Table 3 considers these, comparing customer experience, business model prospects and challenges faced by each.

Table 3 Comparison of potential range anxiety solutions

\begin{tabular}{|c|c|c|c|}
\hline & Customer experience & Business model & Challenges \\
\hline $\begin{array}{l}\text { Range extenders } \\
\text { (in-motion charging } \\
\text { - EP Tender) }\end{array}$ & $\begin{array}{c}\text { Convenience but } \\
\text { potential } \\
\text { manoeuvrability issues }\end{array}$ & $\begin{array}{l}\text { No high infrastructure } \\
\text { costs but dependent } \\
\text { on critical mass of } \\
\text { customers }\end{array}$ & $\begin{array}{l}\text { Partnership with } \\
\text { vehicle } \\
\text { manufacturers }\end{array}$ \\
\hline $\begin{array}{l}\text { Range extenders } \\
\text { (charging service - } \\
\text { Mobat) }\end{array}$ & $\begin{array}{l}\text { Provides additional } \\
\text { charging option }\end{array}$ & $\begin{array}{l}\text { Feasibility dependent } \\
\text { on customer numbers }\end{array}$ & $\begin{array}{l}\text { Still involves lengthy } \\
\text { stops on long } \\
\text { journeys }\end{array}$ \\
\hline Battery swapping & $\begin{array}{l}\text { Swapping process fast } \\
\text { but dependent on } \\
\text { adequate swapping } \\
\text { station infrastructure }\end{array}$ & $\begin{array}{l}\text { Business models for } \\
\text { private cars have } \\
\text { failed }\end{array}$ & $\begin{array}{l}\text { High costs involved } \\
\text { in building swapping } \\
\text { infra-structure }+ \\
\text { compatibility issues }\end{array}$ \\
\hline Hybrid vehicles & $\begin{array}{c}\text { Flexible and } \\
\text { convenient car use }\end{array}$ & $\begin{array}{l}\text { A growing and } \\
\text { profitable market }\end{array}$ & $\begin{array}{c}\text { Less environmental } \\
\text { impact as still } \\
\text { involves } \mathrm{CO} 2 \\
\text { emissions }\end{array}$ \\
\hline
\end{tabular}

Both evidence from the patent analysis, and from Table 3, indicates that in considering the different range anxiety solutions the one that appears to have the best prospects is the continuing development of hybrids. This is the option which offers most driver convenience although, in sustainability terms, it is less impactful as it involves the incorporation of an ICE engine, albeit reduced in size. An important background to the developments analysed in this paper is the wider context of battery development which is being watched closely, and invested in heavily, by vehicle manufacturers. Despite 
substantial investment, improvements in battery energy density have been slow. Progress has been made but at a high cost premium and longer range batteries for smaller, affordable cars, remain elusive.

How vehicle manufacturers perceive the prospects for battery development is also important and will be affected by information from their own $\mathrm{R}+\mathrm{D}$ departments and outside consultants. Decision making processes within large firms are also subject to organisational inertia (Chesbrough, 2007) and a reluctance to take risks amongst car firm executives. For these reasons vehicle manufacturers can be characterised as following a 'wait-and-see' approach, their hope being that a transition to EVs will take place with as limited a change to the traditional driver experience offered by ICEs as possible. It is for this reason that the developers of external range extenders have found it difficult to form partnerships with larger firms.

In conclusion this paper has focussed on the issue of 'range anxiety' and EVs. This is a problem that has been identified as an important one for the future of smarter and more sustainable urban mobility as range remains a barrier to the wider acceptance of EVs. The paper has concentrated on one particular approach to the range issue, that of external range extenders. Patent analysis and Social Network Analysis has revealed how the large vehicle manufacturers have only a very limited interest in developing this technology and that the technological development that has taken place is mostly incremental in nature and relating to the development of hybrid propulsion systems.

Qualitative analysis has revealed how innovation in developing external range extenders has come from small firms but also how they faced significant difficulties in persuading large firms to collaborate on developing and implementing the technology. It is for this reason one of the firms, BVB Innovate, has shifted its focus away from in-motion charging to, instead, using its range extenders as a mobile 'charge-anywhere' service. Underlying all attempts to deal with the range problem is the preference of vehicle manufacturers to wait for developments in battery density even though the length of this wait for these, and the price obstacles involved, are unknown.

\section{Acknowledgements}

Thanks to the British Academy/SAMS Small Grant which was awarded to Dr Ian Clarke and Dr Athena Piterou between January 2015 and September 2016 and which allowed this research to take place. Thanks also to representatives from EP Tender (France) and BVB Innovate (Germany) for agreeing to be interviewed for this research.

\section{References}

Agnolucci, P. and McDowall, W. (2007) 'Technological change in niches: auxiliary power units and the hydrogen economy', Technological Forecasting and Social Change, Vol. 74, No. 8, pp.1394-1410.

Baden-Fuller, C. and Haefliger, S. (2013) 'Business models and technological innovation', Long Range Planning, Vol. 46, No. 6, pp.419-426.

Beaudry, C. and Schiffauerova, A. (2011) 'Impacts of collaboration and network indicators on patent quality: the case of Canadian nanotechnology innovation', European Management Journal, Vol. 29, No. 5, pp.362-376. 
Boons, F. and Lüdeke-Freund, F. (2013) 'Business models for sustainable innovation: state-of-the-art and steps towards a research agenda', Journal of Cleaner Production, Vol. 45, No. 2, pp.9-19.

Bunzeck, I., Feenstra, Y.C.F.J. and Paukovic, M. (2011) Preferences of Potential Users of Electric Cars Related To Charging - A Survey in 8 European Countries G4V: Grid for Vehicles [online] http://www.d-incert.nl/wp-content/uploads/2011/05/rapportage_ECN.pdf (accessed 14 December 2017).

Chesbrough, H. (2007) 'Business model innovation: it's not just about technology anymore', Strategy \& Leadership, Vol. 35, No. 6, pp.12-17.

Cozzens, S., Gatchair, S., Kang, J., Kim, K.S., Lee, H.J., Ordóñez, G. and Porter, A. (2010) 'Emerging technologies: quantitative identification and measurement', Technology Analysis \& Strategic Management, Vol. 22, No. 3, pp.361-376.

Demil, B. and Lecocq, X. (2010) 'Business model evolution: in search of dynamic consistency', Long Range Planning, Vol. 43, Nos. 2-3, pp.227-246.

Dijk, M. (2016) 'Electric revenge after 100 years? Comparing car market patterns around 1900 and 2000', International Journal of Automotive Technology and Management, Vol. 16, No. 2, pp.147-168.

European Patent Office (EPO) (n.d.) Patent Families [online] https://www.epo.org/searching-forpatents/helpful-resources/first-time-here/patent-families.html (accessed 16 March 2018).

Firm Interview 1 (2016) Interview conducted with EP Tender Representative, Poissy, France June.

Firm Interview 2 (2016) Interview conducted with BVB Innovate Representative, Stuttgart, Germany, October.

Frank, T., Neumann, I., Buhler, F., Cocron, P. and Krem, J.F. (2012) 'Experiencing range in an electric vehicle: understanding psychological barriers applied psychology', An International Review, Vol. 61, No. 3, pp.368-391.

Franke, T. and Krems, J.F. (2013a) 'What drives range preferences in electric vehicle users?', Transport Policy, Vol. 30, No. 6, pp.56-62.

Franke, T. and Krems, J.F. (2013b) 'Understanding charging behaviour of electric vehicle users', Transportation Research Part F: Traffic Psychology and Behaviour, Vol. 21, No. 6, pp.75-89.

Graham-Rowe, E., Gardner, B., Abraham, C., Skippon, S., Dittmar, H., Hutchins, R. and Stannard, J. (2012) 'Mainstream consumers driving plug-in battery-electric and plug-in hybrid electric cars: a qualitative analysis of responses and evaluations', Transportation Research Part A: Policy and Practice, Vol. 46, No. 1, pp.140-153.

Griliches, Z. (1990) 'Patent statistics as economic indicators: a survey', Journal of Economic Literature, Vol. 28, No. 4, pp.1661-1707.

Harrop, P. (2018) Range Extenders for Electric Vehicles Land, Water \& Air 2018-2028. Technologies, Players, Market Forecasts [online] https://www.idtechex.com/research/ reports/range-extenders-for-electric-vehicles-land-water-and-air-2018-2028-000558.asp (accessed 24 February 2018).

Hopkins, M.M. and Siepel, J. (2013) 'Just how difficult can it be counting up R\&D funding for emerging technologies (and is tech mining with proxy measures going to be any better)?', Technology Analysis \& Strategic Management, Vol. 25, No. 6, pp.655-685.

IPC Green Inventory (n.d.) [online] http://www.wipo.int/classifications/ipc/en/est/ (accessed 24 February 2018).

Kessler, T. and Stephan, M. (2013) 'Service transition in the automotive industry', International Journal of Automotive Technology and Management, Vol. 13, No. 3, pp.237-256.

Kley, F., Lerch, C. and Dallinger, D. (2011) 'New business models for electric cars - a holistic approach', Energy Policy, Vol. 39, No. 6, pp.3392-3403.

Krommes, S. and Schmidt, F. (2017) 'Business model analysis of electric mobility products and services', International Journal of Automotive Technology and Management, Vol. 17, No. 3, pp.316-338. 
Kurani, K.S., Turrentine, T. and Sperling, D. (1996) 'Testing electric vehicle demand in 'hybrid households' using a reflexive survey', Transportation Research Part D: Transport and Environment, Vol. 1, No. 2, pp.131-150.

Leydesdorff, L. (2004) 'The university-industry knowledge relationship: analyzing patents and the science base of technologies', Journal of the American Society for Information Science and Technology, Vol. 55, No. 11, pp.991-1001.

Lieven, T., Mühlmeier, S., Henkel, S. and Waller, J.F. (2011) 'Who will buy electric cars? An empirical study in Germany', Transportation Research Part D: Transport and Environment, Vol. 16, No. 3, pp.236-243.

Lo Storto, C. (2006) 'A method based on patent analysis for the investigation of technological innovation strategies: the European medical prostheses industry', Technovation, Vol. 26, No. 8, pp.932-942.

Mogoutov, A., Cambrosio, A., Keating, P. and Mustar, P. (2008) 'Biomedical innovation at the laboratory, clinical and commercial interface: a new method for mapping research projects, publications and patents in the field of microarrays', Journal of Informetrics, Vol. 2, No. 4, pp.341-353.

Needell, Z.A., McNerney, J., Chang, M.T. and Trancik, J.E. (2016) 'Potential for widespread electrification of personal vehicle travel in the United States', Nature Energy, Vol. 1, No. 9, p.16112.

Nilsson, M. (2011) Electric Vehicles: The Phenomenon of Range Anxiety ELVIRE Consortium [online] http://e-mobility-nsr.eu/fileadmin/user_upload/downloads/info-pool/the phenomenon_of_range_anxiety_elvire.pdf(accessed 12 November 2017).

OECD (n.d.) Glossary of Patent Terminology [online] https://www.oecd.org/sti/sci-tech/ 37569498.pdf (accessed 16 March 2018).

Orsato, R.J. and Wells, P. (2007) 'The automobile industry \& sustainability', Journal of Cleaner Production, Vol. 15, Nos. 11-12, pp.989-1184.

Pearre, N.S., Kempton, W., Guensler, R.L. and Elango, V.V. (2011) 'Electric vehicles: how much range is required for a day's driving?', Transportation Research Part C: Emerging Technologies, Vol. 19, No. 6, pp.1171-1184.

Pilkington, A. and Dyerson, R. (2006) 'Innovation in disruptive regulatory environments: a patent study of electric vehicle technology development', European Journal of Innovation Management, Vol. 9, No. 1, pp.79-91.

Pilkington, A., Dyerson, R. and Tissier, O. (2002) 'The electric vehicle: patent data as indicators of technological development', World Patent Information, Vol. 24, No. 1, pp.5-12.

Proff, H. and Fojcik, T.M. (2015) 'Business model innovations in times of long-term discontinuous technological change-an empirical examination of the automotive industry in transition to electric mobility', International Journal of Automotive Technology and Management, Vol. 15, No. 4, pp.418-442.

Ranaei, S., Karvonen, M., Suominen, A. and Kässi, T. (2016) 'Patent-based technology forecasting: case of electric and hydrogen vehicle', Int. J. Energy Technology and Policy, Vol. 12, No. 1, pp. $20-40$.

Rauh, N., Franke, T. and Krems, J.F. (2015) 'Understanding the impact of electric vehicle driving experience on range anxiety', Human Factors, Vol. 57, No. 1, pp.177-187.

Rezvani, Z., Jansson, J. and Bodin, J. (2015) 'Advances in consumer electric vehicle adoption research: a review and research agenda', Transportation Research Part D: Transport and Environment, Vol. 34, No. 1, pp.122-136.

Rotolo, D., Hicks, D. and Martin, B.R. (2015) 'What is an emerging technology?', Research Policy, Vol. 44, No. 10, pp.1827-1843.

Segard, J-B. and Baumgärtner, M. (2015) Modular Energy For Electric Vehicles: A Paradigm Shifting Innovation for the Transport Sector [online] http://www.eptender.com/SiteAssets/ EEVC\%20paper\%20EP\%20Tender\%20-\%20Nomadic\%20Power.pdf (accessed 3 December 2017). 
Small, H., Boyack, K.W. and Klavans, R. (2014) 'Identifying emerging topics in science and technology', Research Policy, Vol. 43, No. 8, pp.1450-1467.

Stringham, E.P., Miller, J.K. and Clark, J.R. (2015) 'Overcoming barriers to entry in an established industry: Tesla Motors', California Management Review, Vol. 57, No. 4, pp.85-103.

Veefkind, V., Hurtado-Albir, J., Angelucci, S., Karachalios, K. and Thumm, N. (2012) 'A new EPO classification scheme for climate change mitigation technologies.', World Patent Information, Vol. 34, No. 2, pp.106-111.

Verspagen, B. (2007) 'Mapping technological trajectories as patent citation networks: a study on the history of fuel cell research', Advances in Complex Systems, Vol. 10, No. 1, pp.93-115.

Wang, H. and Kimble, C. (2011) 'Leapfrogging to electric vehicles: patterns and scenarios for China's automobile industry', International Journal of Automotive Technology and Management, Vol. 11, No. 4, pp.312-325.

Weiller, C., Shang, T., Neely, A. and Shi, Y. (2015) Competing and co-existing business models for EV: lessons from international case studies', International Journal of Automotive Technology and Management, Vol. 15, No. 2, pp.126-148.

Wells, P. and Nieuwenhuis, P. (2012) 'Transition failure: understanding continuity in the automotive industry', Technological Forecasting and Social Change, Vol. 79, No. 9, pp.1681-1692.

Wells, P.E. (2010) The Automotive Industry in an era of Eco-Austerity: Creating and Industry as if the Planet Mattered, Edward Elgar, Cheltenham.

Wesseling, J.H., Faber, J. and Hekkert, M.P. (2014) 'How competitive forces sustain electric vehicle development', Technological Forecasting and Social Change, Vol. 81, No. 1, pp.154-164.

World Intellectual Property Organisation (WIPO) (n.d.) Protecting Innovations by Utility Models. What is a Utility Model? [online] http://www.wipo.int/sme/en/ip_business/utility_models/ utility_models.htm (accessed 16 March 2018).

World Intellectual Property Organisation WIPO (n.d.) Frequently asked Questions on Patents: SMEs [online] http://www.wipo.int/sme/en/faq/patent_faqs.html (accessed 16 March 2018).

\section{Appendix}

\section{Patent search scripts}

The patent search was conducted using the Patseer patent search and analysis software. At the time of search Patseer Standard Editions provided extensive bibliographic coverage from more than a hundred patent authorities including full-text coverage from 19 patent authorities. Initially, the search included the terms 'range extender' and 'EV' (or car/automobile). However, the initial search resulted in only a limited list of records. Considering that the terminology is not fixed, terms synonymous with range extender were used in order to capture a wide variety of records. The textual search was conducted in the fields of title, abstract and claims. The search strategy relied more on text-based search rather than patent classification. Searching by patent classification risks the inclusion of irrelevant patents as patent classes do not always refer to the type of vehicles where the technology is applied: the main purpose of classifications is to archive patents rather than identify emerging technologies (Wesseling et al., 2014). In addition, many patents in the field are included in more than one class (ibid.), although it would be possible to focus on the primary class only. An examination of the patent classifications referring to EVs (CPC and IPC class B60L: electric equipment or propulsion of electrically propelled vehicles; magnetic suspension or levitation for vehicles; 
electrodynamic brake systems for vehicles, in general) identified the following subgroups relating to range extenders B60L 11/123 and B60L 11/126 which include patents referring to electric propulsion with power supplied within the vehicle using range extenders, e.g., series hybrid vehicles and in the case of B 60L 11/126 subgroup the range extender has lower power output with respect to the total power output of the vehicle. However, these subgroups include technologies that would be best described as forms of hybrid vehicles rather than as battery EVs which use a range extender as an auxiliary unit in order to resolve the problem of range anxiety for longer journeys. The search was conducted in records from all patent authorities covered by Patseer, including applications submitted through the European route and WIPO. The application number was used to deduplicate the results so as to avoid double counting the patent and the application, and to avoid the inclusion of multiple patent kind codes. The record with the earliest application date was selected.

The following search script was used: TAC: ((range_extender OR (trailer ws (generat * OR power source)) OR (gen *_set ws external)) AND electric WS2 (vehicle OR car OR automobile)). No temporal or geographical limits were applied.

The search uses Boolean operators.

TAC (Title, Abstract\& Claims): the fields used for the search.

WS indicates that the terms should be included in the same sentence.

Wild card character symbol *.

This search resulted in a more comprehensive set of results than simply using the terms range extender. The use of the term trailer in the same sentence as power generator/generation or power source would indicate that the trailer functions as a range extender. Finally, the term external generator set or gen set is also used to refer to range extenders by some companies so they were included as alternatives. 